\title{
Cure Kinetics and Properties of Blends of Epoxy Resins with Polyethersulfone
}

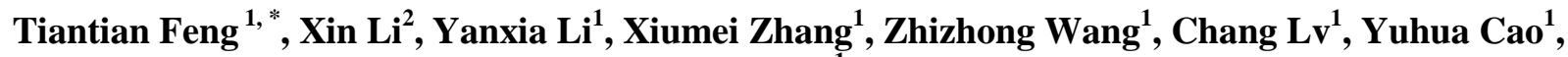 \\ Lin $\mathbf{L i}^{1}$ \\ ${ }^{I}$ Faculty of Mechanical and Electrical Engineering, Guangdong Baiyun University, Guangzhou, \\ Guangdong, China \\ ${ }^{2}$ China Petroleum Engineering and Construction Corporation. North China Company, Cangzhou, Hebei, \\ China \\ *Corresponding Author.
}

\begin{abstract}
In this article, polyethersulfone and flourene-coating epoxy resin were utilized to modify both the toughness and the mechanical properties of traditional epoxy resins. The cure kinetics and the thermal stability of the resulted blends were tested by differential scanning calorimetry technology and thermogravimetric analysis, respectively. Additionally, the mechanical properties of resulted thermosets were discussed after tested by Dynamic Thermomechanical Analyzer. When compared to the traditional epoxides, the obtained blends exhibit much better heat resistance, thermal stability and mechanical properties.
\end{abstract}

Keywords: Epoxy resins, mechanical properties, curing behavior

\section{Introduction}

Epoxy resins are attractive thermosets because of their excellent properties, for example, high mechanical properties and good insulation performance. Thus, they are widely used in forming copper clad laminate, producing molded product, and taking as the matrix resin for advanced composite materials and so on. However, the brittleness has limited their applications in forming films. Nowadays, many engineering thermoplastics are preferable materials as modifiers due to their high modulus, good toughness, and better heat resistance. A series of high-ductile thermoplastics, for example, poly (ether ether ketone), polysulfone and polyethersulfone, have been utilized in modification of epoxy resins [1-5].

Recently, a novel high performance epoxide, diglycidyl ether of 9, 9-bis (4-hydroxyphenyl)-flourene (DFE) has drawn a widely public attention since the incorporation of fluorene moieties endow its cured resin many excellent properties, for example, high thermal stability and good moisture resistance. According to the literature, DFE was obtained by 9, 9-bis (4-hydroxyphenyl)-flourene and chloroepoxy propane with the addition of sodium hydroxide [6]. However, the superiority compared to conventional resins can't cater to all the needs of high-performance resins and the high cost of raw materials has restricted the use of DFE.

In order to obtain a series of high performance thermosets, both polysulfone and DFE were used as modifiers to improve the properties to traditional epoxy (E-51) in this article. The curing behavior, cure kinetics, thermal and mechanical properties of the resulted epoxides were also discussed.

\section{Experimental}

2.1 Materials

ISSN: 0010-8189

(C) CONVERTER 2020

Www.converter-magazine.info 
The DFE with an epoxy value of 0.40 and a melting point of $133-135{ }^{\circ} \mathrm{C}$ was synthesized by 9, 9-bis (4hydroxyphenyl)-fluorene and chloroepoxy propane as reported [6]. The engineering plastic, polyethersulfone (PES) was used as one of the modifiers. The structures of PES and DFE were shown in Figure 1. In addition, 4, 4'diamino-diphenyl-sulfone (DDS) was taking as curing agent. In this paper, PES, DDS, E-51and other reagents and solvents were purchased from Aladdin Company and used without further purification.

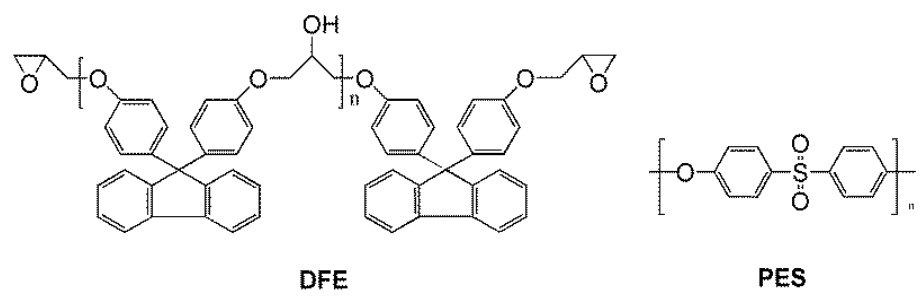

Figure 1: The structures of DFE and PES

\subsection{Blend preparation}

The mixtures were blending on a melting-point apparatus. Due to the melting point of DFE is $132{ }^{\circ} \mathrm{C}$, the pure DFE mixed with PES is hard to operate with a high mixing temperature of $220{ }^{\circ} \mathrm{C}$. Some paper advanced to use methylene dichloride to dissolve resin and curing agent, but the solvent cannot be lustrated in the vacuum since the film above the surface which is formed by the mixture can prevent methylene dichloride evaporating. In this study, E-51, DFE, PES and DDS were blending together at $160{ }^{\circ} \mathrm{C}$ with a constant stirring since the traditional epoxy resin can depress the mixed temperature. The mixtures were transparent and uniform without phase separation. The obtained samples were listed in Table 1.

Table 1. The formulation of samples

\begin{tabular}{|c|c|c|c|}
\hline Samples & DFE & E-51 & PES \\
\hline A0 & 100 & 0 & 0 \\
\hline A1 & 100 & 0 & 10 \\
\hline A2 & 80 & 20 & 10 \\
\hline A3 & 60 & 40 & 10 \\
\hline A4 & 40 & 60 & 10 \\
\hline
\end{tabular}

\subsection{Characterizations}

Differential scanning calorimetry technology (DSC, TA Q200), differential scanning calorimetry technology (DMA, TA Q50) and thermogravimetric analysis (TGA, TA Q50) were used to discuss the curing behavior, cure kinetics, thermal and mechanical performance of resulted epoxy blends.

\section{Results and Discussion}

\subsection{Melting temperature}

The result is showed in Table 2.

Table 2. The relationship between mixed temperature and content of E-51

\begin{tabular}{|c|c|}
\hline Sample Name & Mixed tempetature $/{ }^{\circ} \mathrm{C}$ \\
\hline DFE/DDS & 180 \\
\hline $\mathrm{DFE} / \mathrm{PES}_{10} / \mathrm{DDS}$ & 220 \\
\hline DFE $_{80}$ E-51 $_{20} / \mathrm{PES}_{10} / \mathrm{DDS}$ & 180 \\
\hline $\mathrm{DFE}_{60} \mathrm{E}_{-51_{40} / \mathrm{PES}_{10} / \mathrm{DDS}}$ & 150 \\
\hline
\end{tabular}

ISSN: 0010-8189 
From the Table 2, we can obtain that E-51 can drastically decrease the mixed temperature. The reason can be explained that E-51 is a liquid resin and it can solve DFE and PES acutely. Whereas, the mixed temperature reduce was at the expense of increase in the E-51 content. In addition, the mixed temperature do not greatly reduced any more when the E-51 content rise to $60 \mathrm{wt} \%$.

\subsection{DSC studies}

Dynamic non-isothermal DSC studies were done for the DFE +PES+DDS mixture with various heating rates of 20, 15, 10 and $5{ }^{\circ} \mathrm{C} / \mathrm{min}$. The obtained curves are exhibited in Figure 2. From Figure 2, we can find that the peak temperature decreased as the heating rate lowered. In addition, the curing temperature from the DSC curves of the samples can be deduced. The curing temperature of mixtures was $150^{\circ} \mathrm{C} / 1 \mathrm{~h}+190{ }^{\circ} \mathrm{C} / 2 \mathrm{~h}+240^{\circ} \mathrm{C} / 1 \mathrm{~h}$.

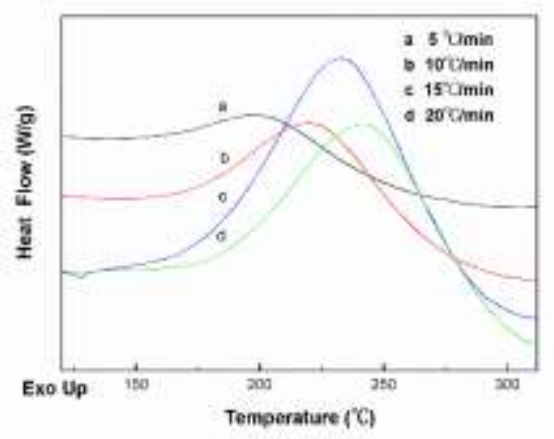

Figure 2: Dynamic non-isothermal DSC curves

As reported, the curing reactions reflected the apparent activation energy $\Delta \mathrm{E}$ was deduced by the Kissinger equation [5].

$$
\frac{d\left[\ln \left(\beta / T_{P}{ }^{2}\right)\right]}{d\left[1 / T_{P}\right]}=-\frac{\Delta E}{R}
$$

$\beta$ : the heating rate $\left({ }^{\circ} \mathrm{C} / \mathrm{min}\right)$;

$\Delta E$ : the apparent activation energy $(\mathrm{kJ} / \mathrm{mol})$;

$T_{p}$ : the peak temperature $(\mathrm{K})$;

$R$ : a gas constant, $8.1314 \mathrm{~J} / \mathrm{mol} \cdot \mathrm{K}$.

According to the different heating rate of value from $\ln \left(\beta / T p^{2}\right)$ against $1 / T p$ plot for samples $\mathrm{A} 0 \sim \mathrm{A} 4$, some straight lines can be obtained. What's more, the slopes of these curves were concluded to calculate $\Delta \mathrm{E}$.

The reaction order of curing chemical reaction can be deduced from Crane equation.

$$
\begin{gathered}
\Delta \ln \beta / \Delta\left(\frac{1}{T_{p}}\right)=-\left(\frac{\Delta E}{n R}+2 T_{p}\right) \\
\frac{\Delta E}{n R}>>2 T_{p} \\
\Delta \ln \beta / \Delta\left(\frac{1}{T_{p}}\right)=-\left(\frac{\Delta E}{n R}+2 T_{p}\right) \approx-\frac{\Delta E}{n R}
\end{gathered}
$$

ISSN: 0010-8189 
The calculated kinetic parameters were summarized in Table 3. The results show that $\Delta E$ increased about $1 \mathrm{~kJ} \cdot \mathrm{mol}^{-1}$, and the reaction order of curing chemical reaction $n$ is about 0.9 .

Table 3 The calculated kinetic parameters

\begin{tabular}{|c|c|c|c|c|c|}
\hline $\begin{array}{c}\text { Sample } \\
\text { NO. }\end{array}$ & $-\ln \beta / T_{\mathrm{p}}^{2}-1 / T_{p}$ & $\Delta E / \mathrm{kJ}^{\mathrm{mol}}{ }^{-1}$ & $\ln \beta-1 / T_{p}$ & $n$ & Kinetic equation \\
\hline A0 & 7.049 & 58.605 & -8.059 & 0.875 & $-\frac{d \alpha}{d t}=\kappa(1-\alpha)^{0.875}$ \\
\hline A1 & 7.159 & 59.520 & -8.149 & 0.879 & $-\frac{d \alpha}{d t}=\kappa(1-\alpha)^{0.879}$ \\
\hline A2 & 9.975 & 82.932 & -10.988 & 0.908 & $-\frac{d \alpha}{d t}=\kappa(1-\alpha)^{0.879}$ \\
\hline A3 & 8.462 & 70.353 & -9.479 & 0.893 & $-\frac{d \alpha}{d t}=\kappa(1-\alpha)^{0.879}$ \\
\hline A4 & 7.685 & 63.893 & -8.681 & 0.885 & $-\frac{d \alpha}{d t}=\kappa(1-\alpha)^{0.879}$ \\
\hline
\end{tabular}

\subsection{Dynamic mechanical thermal analysis studies}

The heat resistance and mechanical properties were tested by DMA. The tan $\delta$ versus temperature plots are shown in Figure 3(b). From Figure 3(b), we can see only one $\tan \delta$ peak appears at $200 \sim 300{ }^{\circ} \mathrm{C}$, meaning that there was no phase separation occurs in the mixture. In addition, the glass transition temperature $\left(T_{\mathrm{g}}\right)$ of mixtures hold the line of $260{ }^{\circ} \mathrm{C}$ with the increase of PES, which means that the addition of PES has little influence on the heat resistance of obtained resins.
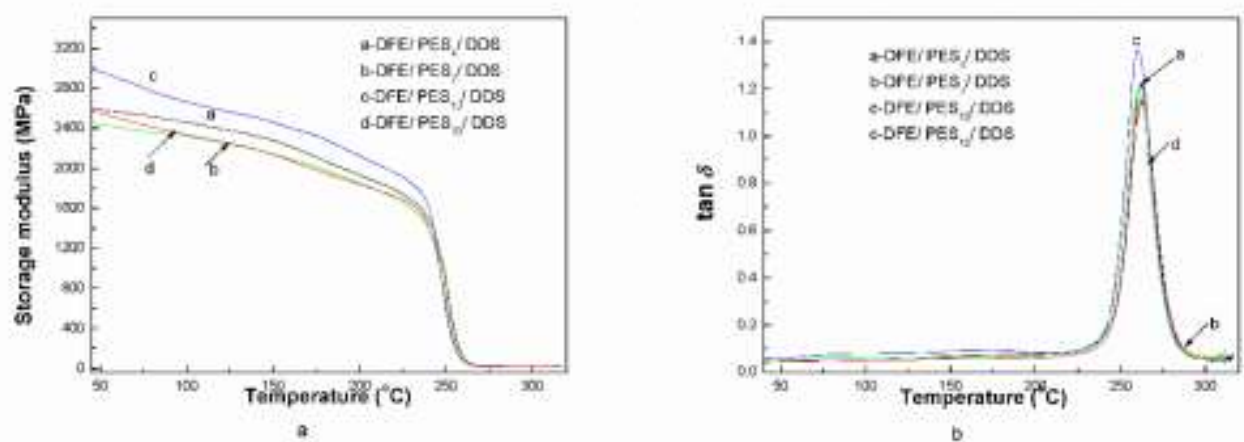

b

Figure 3: a: Storage modulus versus temperature plot for 4, 7, 10, 13wt\% PES modified neat DFE b: Tan $\delta$ versus temperature plot for 4, 7, 10, 13wt\% PES modified neat DFE

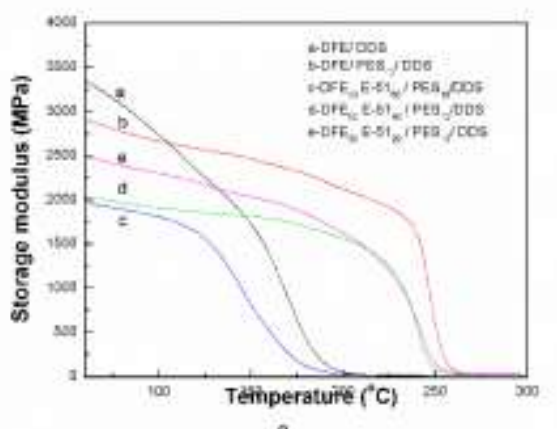

a

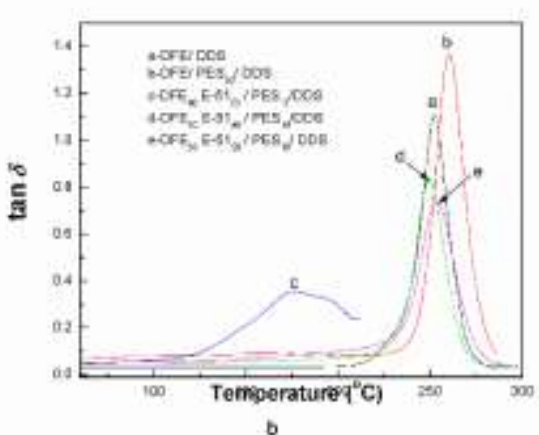

b

ISSN: 0010-8189

Www.converter-magazine.info 
Figure 4: a: Storage modulus versus temperature plot for neat resin, contnet of 0,20,40,60 wt\% E-51 cured with $D D S$

b: Tan $\delta$ versus temperature plot for neat resin, contnet of 0,20,40,60 wt\% E-51 cured with DDS

When the E-51 added in 20, $40 \mathrm{wt} \%$, the $T_{\mathrm{g}}$ cut down about $10{ }^{\circ} \mathrm{C}$, compared to neat DFE mixed PES. And it did not lower than nonmodified resin. But it had an enormous lost when the content of E-51 reached to $60 \mathrm{wt} \%$. All of it can achieve visually from Fig 4(b).

The storage modulus of resin matrixes decrease, compared to neat DFE cured with DDS. From Fig 3(a), the relationship between the storage modulus and content of PES is without rules. But the downtrend of it is in a line. The storage modulus of resin matrix mixed with E-51 appeared excellent rules. From Fig 4(a), we can obtained that the neat resin cured with DDS is maximum. The storage modulus decrease with the content of E-51 increased.

\subsection{Thermogravimetry analysis studies}

In order to investigated the heat resistance of mixture, we carried out the experiment in four heat rate $(5,10,15,20$ ${ }^{\circ} \mathrm{C} / \mathrm{min}$ ), the results showed in Fig 5(a). The formulation of thermal degradation has been discussed in the paper of Sunnan Tiptipakorn [7] and the thermal degradation energy of mixture was calculated by the Kissinger method.

From Kissinger method, Eq. (4) is used to determine the thermal degradation energy of solid state reactions.

$$
\ln \left(\frac{\beta}{T_{p}^{2}}\right)=\ln \frac{A R}{E a}+\ln \left[n\left(1-\alpha_{p}\right)^{n-1}\right]-\frac{E a}{R T_{p}}
$$

Where $T_{p}$ is the absolute temperature, $\alpha_{p}$ is the weight loss at maximum weight-loss rate $(d \alpha / d t)_{p}$, and $n$ is the reaction order, respectively.

From the slope of the straight line $\ln \left(\beta / T p^{2}\right)$ divided $1 / T_{p}$, the thermal degradation energy can be obtained. The data were summarized in Table 4 . The thermal degradation energy $\left(E_{a}\right)$ reached to $141.18 \mathrm{~kJ} / \mathrm{mol}$. It has preferable thermal stability.

Table 4. Thermal degradation data of 10wt $\%$ PES modified DFE cured with DDS

\begin{tabular}{|c|c|c|c|c|c|}
\hline$\beta / \mathrm{C} \cdot \mathrm{min}^{-1}$ & $T_{p} / \mathrm{K}$ & $\alpha_{p} / \mathrm{g} \cdot \mathrm{min}^{-1}$ & $\ln \left(\beta / T_{p}^{2}\right)$ & $1000 / T_{p}$ & $E_{a} / \mathrm{kJ} \cdot \mathrm{mol}^{-1}$ \\
\hline 5 & 652.247 & 61.571 & -11.351 & 1.533 & \\
\cline { 1 - 5 } 10 & 667.905 & 33.321 & -10.706 & 1.499 & \multirow{2}{*}{141.18} \\
\hline 15 & 676.042 & 22.446 & -10.324 & 1.479 & \\
\hline 20 & 686.941 & 18.071 & -10.069 & 1.456 & \\
\hline
\end{tabular}
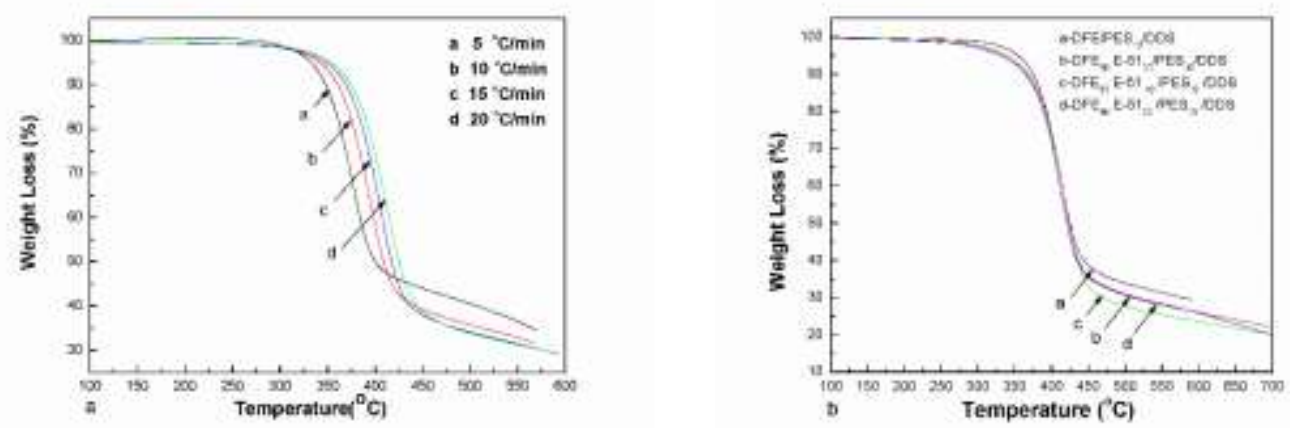

Figure 5: a: TGA thermograms of 10wt\% PES modified with DFE at differnet heat rate.

$b: T G A$ thermograms of the relationship between the content of E-51 and the anaerobic char yields.

ISSN: 0010-8189 
The results of added E-51 was showed in Fig 5(b). The anaerobic char yields at $580{ }^{\circ} \mathrm{C}$ have little decline with the increase of E-51.But the extent is not obviously when the content reached to $60 \mathrm{wt} \%$.

\section{Conclusion}

In the blending systems of PES modified DFE cured with DDS, the content of PES has little effect to the Tg. And neat DFE blended with PES is hard to operating, the mixture temperature as high as $220{ }^{\circ} \mathrm{C}$. With E-51 adding, it has acutely decline. When added about $40 \mathrm{wt} \% \mathrm{E}-51$, the operation temperature cut down about $70{ }^{\circ} \mathrm{C}$. But the $T_{\mathrm{g}}$ only declined about $2.5^{\circ} \mathrm{C}$, compared with neat resin.

\section{Acknowledgements}

This research were supported by the foundation of Young Innovative Talents in General Colleges of Guangdong Province (Project No. 2018KQNCX298), Guangdong Province Fresh Vegetable Preservation and Packaging Equipment Engineering Research Center (Project No. 2019GCZX008) and the Scentific Research Foundation of Guangdong Baiyun University.

\section{References}

[1] K. Mimure, H. Ito, H. Fujioke, "Improvement of thermal and mechanical properties by control of morphologies in PES-modified epoxy resins," Polymer, vol. 41, no. 12, pp. 4451-4459, 2000.

[2] B. Francis, G. V. Poel, F. Posadb, et al., "Cure kinetics and morphology of blends of epoxy resin with poly (ether ether ketone) containing pendant tertiary butyl groups,” Polymer, vol. 44, no. 13, pp. 36873699, 2003.

[3] B. Fernándz, A. Arbelaz, E. Diaz, et al., "Influence of polyethersulfone modification of a tetrafunctional epoxy matrix on the fracture behavior of composite laminates based on woven carbon fibers," Polymer Composites, vol. 25, no. 5, pp. 480-488, 2004.

[4] M. Jimenez, S. Duquesne, S. Bourbigot, "Kinetic analysis of the thermal degradation of an epoxybased intumescent coating," Polymer Degradation and Stability, vol. 94, no. 3, pp. 404-409, 2008.

[5] A. Motahari, A. A. Rostami, A. Omrani, et al., "On the thermal degradation of a novel epoxy-based nanocomposite cured with tryptophan as an environment-friendly curing agent," Journal of Macromolecular Science, Part B, vol. 54, no. 5, pp. 517-532, 2015.

[6] W. Li, J. Wan, Q. H. Qin, et al., "Synthesis and characterization of 9,9-bis(4-hydroxypheenyl)-fluorene catalyzed by cation exchanger," Pigment \& Resin technology, vol. 37, no. 1, pp. 9-15, 2008.

[7] S. Tiptipakern, S. Damrengsakkul, S. Ande, et al., "Thermal degradation behaviors of polybenzoxazene and silicon-containing polyimide blends," Polymer Degradation and Stability, vol. 92, no. 7, pp. 1265-1278, 2007. 